\title{
Method for manipulating peak flow measurements producing falsely raised readings
}

\author{
S Ross, D P Cochran
}

\begin{abstract}
Methods by which patients can artificially produce raised peak flow measurements have been described. We recently observed a patient manipulating the peak flow meter in a way that had not been described before. A study was therefore undertaken to determine if this technique could repeatedly produce clinically significant changes in peak flow readings. Fifteen adults, using a mini-Wright peak flow meter, made five measurements using the correct technique followed by five manipulated measurements under observation. Significant increases in peak flow measurements were observed in 14 of the 15 subjects. The mean increase in peak flow rate using the incorrect technique was $56 \%$ (range $-4 \%$ to $86 \%$ ). Clinicians should be aware that patients might employ this technique to manipulate measurements which could have consequences for management.

(Thorax 2001;56:500-501)
\end{abstract}

Keywords: peak flow measurements; technique; false results

Peak flow measurement is used in asthma management. ${ }^{1}$ We are aware that peak flow measurements can be artificially increased by spitting or coughing. ${ }^{2}$ We recently observed a method of manipulating peak flow measurement which has not been previously described.

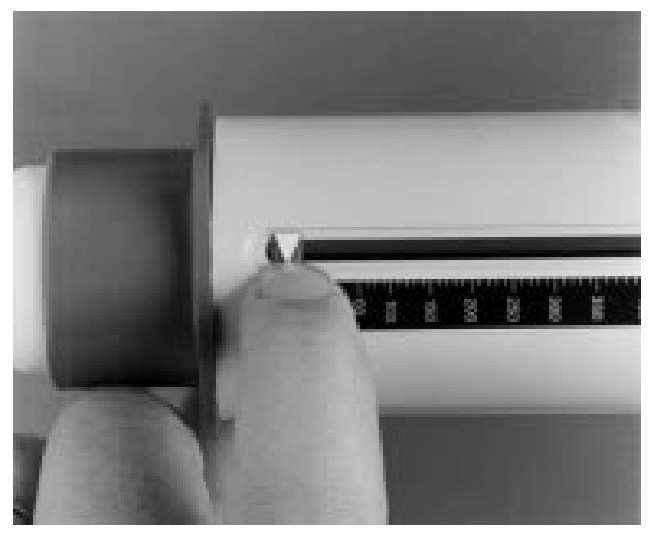

Figure 1 Position of index finger when retarding movement of peak flow indicator.

\section{Case report}

A 13 year old asthmatic boy was seen as an outpatient. He was prone to recurrent acute attacks of asthma and had four hospital admissions in the previous 3 months. The patient was asked to perform a peak flow measurement. During the manoeuvre his movements appeared slightly awkward and, when asked to explain, he admitted that he had discovered that, if he retarded the movement of the peak flow indicator with his index finger at the beginning of the manoeuvre for a fraction of a second after starting to exhale (fig 1), he could increase the reading. $\mathrm{He}$ also explained that, if he moved vigorously during the procedure, it appeared that he was giving maximum effort to performing the measurement and
Department of Paediatrics, Southern General Hospital, Glasgow G51 4TF, UK S Ross

D P Cochran

Correspondence to: Dr D P Cochran bellcochran@supanet.com

Received 22 June 2000 Accepted for publication 15 January 2001
Table 1 Results of peak flow measurements

\begin{tabular}{|c|c|c|c|c|c|c|}
\hline Subject & $\begin{array}{l}\text { Mean of } 5 \\
\text { standard } \\
\text { attempts }\end{array}$ & $\begin{array}{l}\text { Mean of } 5 \\
\text { manipulated } \\
\text { attempts }\end{array}$ & $\begin{array}{l}\text { Relative } \\
\text { increase } \\
(\%)\end{array}$ & $\begin{array}{l}\text { Best of } 5 \\
\text { standard } \\
\text { attempts }\end{array}$ & $\begin{array}{l}\text { Best of } 5 \\
\text { manipulated } \\
\text { attempts }\end{array}$ & $\begin{array}{l}\text { Relative } \\
\text { increase } \\
(\%)\end{array}$ \\
\hline 1 & 509 & 688 & 35 & 520 & $800^{\star}$ & 54 \\
\hline 2 & 500 & 634 & 27 & 520 & 660 & 27 \\
\hline 3 & 613 & 710 & 16 & 625 & $800^{\star}$ & 28 \\
\hline 4 & 516 & 712 & 38 & 590 & $800^{\star}$ & 36 \\
\hline 5 & 490 & 512 & 4 & 510 & 540 & 6 \\
\hline 6 & 526 & 730 & 39 & 530 & $800^{\star}$ & 51 \\
\hline 7 & 628 & 760 & 21 & 640 & $800^{\star}$ & 25 \\
\hline 8 & 548 & 537 & -2 & 575 & 550 & -4 \\
\hline 9 & 414 & 688 & 66 & 420 & 780 & 86 \\
\hline 10 & 439 & 602 & 37 & 450 & $800^{\star}$ & 78 \\
\hline 11 & 402 & 432 & 7 & 410 & 480 & 17 \\
\hline 12 & 522 & 650 & 24 & 540 & $800^{\star}$ & 48 \\
\hline 13 & 468 & 616 & 32 & 480 & 750 & 56 \\
\hline 14 & 432 & 594 & 37 & 440 & $800^{\star}$ & 82 \\
\hline 15 & 294 & 408 & 39 & 350 & 440 & 26 \\
\hline
\end{tabular}

*These subjects produced several peak flow measurements beyond 800 (top of the scale) which were recorded as 800 for the purpose of calculating the mean recording and relative increase. 
this made it difficult for the doctor to detect what he was doing with his finger.

A study was therefore undertaken to determine whether this technique could repeatedly produce clinically significant changes in peak flow readings.

\section{Methods}

Fifteen adults, one of whom had asthma, were asked to make five peak flow measurements in the standard way followed by a further five peak flow measurements by retarding the movement of the peak flow indicator as described in the case report, after an initial practice. All measurements were carried out using a mini-Wright peak flow meter.

\section{Results}

The results are shown in table 1 . Both the mean and the best of five readings for the two techniques were recorded. It can be seen that altering the technique of peak flow measurement (as described in the case study) produced significant increases in peak flow rate in 14 of the 15 subjects. Using the mean of the five attempts, a mean increase of $28 \%$ (range $-2 \%$ to $66 \%$ ) was achieved. When the highest of the five attempts was taken as representative, the mean increase was $56 \%$ (range $-4 \%$ to $85 \%$ ).

\section{Discussion}

Peak flow recording is important in asthma management ${ }^{1}$ and these measurements are used to inform decisions about the need for referral to hospital, admission, and timing of discharge. Patients dislike being in hospital and may be tempted to manipulate peak flow measurements in order to give falsely raised readings that could influence their management. For example, patients may have a true peak flow $<50 \%$ of their personal best but, by falsely increasing the peak flow measurement by $28 \%$, management could be quite different. Clinicians need to be aware of this and of other manoeuvres that lead to falsely raised readings. We would emphasise that it is possible to interfere with the movement of the peak flow indicator with subtlety and this would not be readily noticed unless the clinician is watching closely. Asking patients to "cradle" the peak flow meter with a hand underneath the device is likely to prevent this problem. 1 British Thoracic Society, National Asthma Campaign, Royal college of Physidians of London, et al. The British tion statement. Thorax 1997;52(Suppl 1):S1-21.

2 Strayhorn V, Leeper K, Tolley E, et al. Elevation of peak expiratory flow by a "spitting" maneuver: measured with five peak flow meters. Chest 1998;113:1134-6.

3 Connolly CK. Falsely high PEFR due to acceleration in the mouth. BMF 1987;294:285.

\section{LETTERS TO THE EDITOR}

\section{CFC transition}

Dr Everard wrote such a wide ranging polemic against inhaled therapy that it is difficult to know where to start. While the article contains a good deal of sense, it also contains a number of inaccuracies and misperceptions. I think the record needs to be put straight.

Firstly, Dr Everard says that inhaled insulin will be in use in 2001. However, as far as I am aware, no application for delivery of insulin as an aerosol has yet been submitted to the FDA. New devices for the delivery of insulin are under trial, but the earliest they are likely to get to the market is 2002 . They are likely to be relatively complex devices costing perhaps 100 times more than the current price for a salbutamol metered dose inhaler (MDI).

Secondly, Dr Everard berates the pharmaceutical industry for its efforts in moving away from chlorofluorocarbon (CFC) MDIs. In 1996, when the Montreal protocol came into force, there was a real risk that MDIs for use in asthma/COPD would no longer be available. The industry started 10 years ago to try to reformulate MDIs but the technical challenge has been enormous and complicated by intellectual property issues. Only now, more than a decade later, are a sufficient number of CFC free MDIs coming to the market so that the transition can be completed over the next 2-4 years. This has cost a huge amount of money. But where is the evidence that they prevented new chemical entities for asthma coming to the market? If such clinically efficacious compounds were available, then I am certain that they would have been commercially exploited.

Thirdly, Dr Everard is correct in stating that the MDI in some ways is a less than ideal inhalation device. The new hydrofluorocarbon (HFC) beclomethasone product (Qvar, 3M Pharmaceuticals) has a much smaller particle size, not by design but by necessity. This result in something like 5-6 times more drug being deposited peripherally in the lung but only twice the therapeutic effect compared with the MDI it replaces. This product has given a big "wake up call" to the industry and we should al be asking which particle size really is ideal, particularly for inhaled steroids. Is it different, for example, for beclomethasone versus budesonide versus fluticasone? I am also unaware of any data that monodispersed aerosols are more efficacious or safer than aerosols with a more broad range of particle size.

Fourthly, Dr Everard mixes in with the discussion of technology a rather paternalistic view of patient compliance. If only patients would do as they are told and take their medication all would be well. Does anyone eve complete a course of antibiotics? We badly need more information about why patients do not adhere to medication regimes and what information they need about their disease and the treatments used. But isn't this true for al therapies? Dose counters to improve compliance might be valuable for MDIs - but where is the evidence that they are cost effective, or even that doctors or patients want them?

I am firmly convinced that the MDI, along with the dry powder inhaler (DPI), is here to stay. They are remarkably cheap, instantly effective as bronchodilators, and have an excellent therapeutic ratio for inhaled steroids for most asthmatics. Many patients can use up to 2000 doses per year without their inhaler letting them down, and perhaps it is not surprising that they become reliant on them. Certainly they can be improved upon. Nove devices using aqueous and hydrocarbon propellants are on their way. But if Dr Everard sees any viable and cost effective alternatives, then let us hear about them.

A WOODCOCK Department of Respiratory Medicine, North West Lung Centre, Wythenshawe Hospital, Manchester M23 9LT, UK

1 Everard ML. CFC transition: the Emperor's new clothes. Each class of drug deserves a delivery system that meets its own requirements. Thorax 2000;55:811-4.

Mark Everard's superb leading article ${ }^{1}$ railing against the numerous inadequacies of inhaled therapy delivered by pMDIs is to be applauded, but ultimately is an unsatisfying tract since it does not point to any solutions applicable in the here and now. The single most important advance in the treatment of asthma at the beginning of the 21 st century would be to wean ourselves - and by that I mean the UK since the process is already well advanced in continental Europe-from the use of these archaic impediments to treatment. Everard is right that the regulatory authorities bear a heavy burden of guilt by requiring devices which result in greater lung deposition to undergo much more extensive, and therefore costly, investigation than "me too" devices mimicking the appalling performance of pMDIs. I have witnessed the "detuning" of novel inhalers that he refers to in order to limbo under this bureaucratic hurdle. Removing the equivalence straight jacket for inhaler devices would, at a stroke, allow currently available devices to be used to their maximum and not minimum potential.

Why are the British so hooked on the inadequate and obsolete pMDI? It is simply that 
the currently available alternative-dry powder inhalers - are perceived to be more costly. This view has been led by the Department of Health who have calculated that swapping device for device would cost them a great deal of money. This, however, is the accountancy of the madhouse. Because dry powder inhalers are more efficient at drug delivery, the Fairy Liquid argument holds and the cost of treatment rather than the cost of the device should be used in their calculations. Of course, such back of the cigarette packet arithmetic should be banished by the new god of evidence based medicine. So what is the evidence on cost? Howarth et al have performed an audit of patients who have been transferred to dry powder inhalers because they were unable to use pMDIs. ${ }^{2}$ The cost of treatment with inhaled steroids was actually lower with dry powder inhalers. The only randomised controlled trial using the overpriced Turbohaler came to a similar conclusion. ${ }^{3}$ Thus, what little evidence that is available suggests that prescribing even premium priced dry powder inhalers for the delivery of inhaled steroids may be cheaper than using pMDIs. There can be no argument that there is a cost impediment with the more recent introduction of generic dry powder inhalers which are competitive even on a device for device basis.

Everard rightly points out that the issues of compliance, competence, and contrivance are closely interlinked. What is rarely taken into account in the equation is the patien preference. We have recently analysed the results of three separate studies comparing the market leading pMDI with the Clickhale in terms of patient preference in 118 paediatric and 221 adult patients. ${ }^{4}$ Significantly more $(63 \%)$ preferred the dry powder inhaler to the pMDI $(28 \%)(\mathrm{p}<0.01)$. The dry powder inhaler was also significantly better on other criteria such as ease of use and ease of preparation. Similar results have been obtained in a meta-analysis of comparative studies of 802 patients using the dry powder device Easyhaler. ${ }^{5}$ If patient preference is a surrogate for compliance, then two of Everard's three Cs can be dealt with today by transferring patients not optimally managed on pMDIs to dry powder devices.

The third C-contrivance-will be tackled shortly with the advent of new chip technologies already available in nebulised devices such as the Halolite Adaptive Aerosol Delivery (AAD) system. In Hull, Kastelik and Aziz have recorded patient compliance in 23 subjects using the AAD system and have unsurprisingly found that $20 \%$ of patients were poor compliers $(<70 \%$ of doses). We have been unable to detect this lack of compliance during a formal structured interview or on diary record cards. In future the identification of such problems with smaller devices attached to inhalers will not only be of great medical benefit but also, I suspect, will be led by cost. Vast sums of money are wasted in health care by poor adherence to treatment. The use of such technology may become a financial imperative in the future.

A H MORICE Academic Department of Medicine, The University of Hull, Castle Hill Hospital, Cottingham, East Yorkshire HU16 57O, UK a.h.morice@medschool.hull.ac.uk

1 Everard ML. CFC transition: the Emperor's new clothes. Each class of drug deserves a delivery system that meets its own require-

2 Howarth J, Ledger G, O'Reilly JF. Comparison of benefits and costs of dry powder (DPI) and metered dose (MDI) inhaler treatment of asthma. Eur Respir F 1997;10(Suppl 25): 127s.

3 Liljas B, Stahl E, Pauwels RA. Costeffectiveness analysis of a dry powder inhaler (Turbuhaler) versus a pressurised metered dose inhaler in patients with asthma. Pharmacoeconomics 1997;12:267-77.

4 Morice AH, Stradling JR, Adler LM. Do patients prefer metered dose inhalers (MDI) or dry powder inhalers (DPI)? Eur Respir 72000 ; 16(suppl 31): 98s.

5 Ahonen A, Leinonen M, Ranki-Pesonen $M$. Patient satisfation with EasyhalerTM Patient satisfaction with Easyhaler ${ }^{\mathrm{TM}}$ compared with other inhalation systems in the treatmen of asthma: a meta-analysis. Curr Ther Res Clin

AUTHOR'S REPLY I would like to thank Professors Woodcock and Morice for their thoughts on this subject. The divergence in their views is of interest. Unfortunately, Professor Woodcock appears to have misunderstood the purpose of the article when he characterises it as "polemic against inhaled therapy". The article was written precisely because I do recognise the importance of inhaled therapy and, in particular, the importance of inhaled corticosteroids for the treatment of asthma. Since aerosol therapy is so important, it should be clear that patients deserve to be provided with devices that deliver the drugs reliably and safely to the lungs.

More than a decade ago pharmaceutical companies understandably decided to develop CFC replacement pMDIs. This was not because this was the best solution for patients but because at the time it appeared to be the quickest and cheapest solution. Much to their dismay, they found that this has proved to be a very expensive and long winded exercise. It is, however, important to recognise that the major error in judgement at that time was not that they underestimated the difficulties involved, but the failure to recognise the limitations of the pMDI as a delivery system for drugs other than short acting $\beta$ agonists. The pMDI was a brilliant solution for a particular problem but does not effectively meet the needs of drugs such as inhaled corticosteroids. The challenges for device developers are, firstly, that they must develop a device that can deliver drug effectively to the lungs and, secondly, to produce devices that all patients can and will use effectively. The pMDI and many other technologies can generate aerosols that will deliver drug to the lungs but there has been little effort to meet the second objective. pMDIs are simple to use but very difficult to use effectively. It is inevitable that novel devices will come to the market in coming years, not least because of expiry of drug patents. However, to ensure that all patients derive maximum benefit from this form of therapy in the future it is important to understand the limitation of current delivery systems and to place patient issues squarely at the forefront of future developments. There is now a vast range of novel and impressive technologies available, but unfortunately aerosol scientists appear all too often to be caught up in this exciting technology, forgetting that devices are only there to serve the consumer. The technology is not an end in itself but a means to an end.

The article deliberately avoided proposing specific solutions as the pharmaceutical companies do face many challenges. A major problem is that we do not have a simple method of assessing the "therapeutic index" of a given device so it is very difficult to determine whether a novel device and/or drug is "as safe" as others on the market; the principle of using the "lowest effective dose" therefore remains the best guide. Consideration of the issues of compliance, competence and contrivance are, however, essential if future devices are to meet the needs of patients. The studies Professor Morice cites are certainly a move in the right direction since they attempt to address the relative benefits of drug/device combinations in the real world.

Professor Woodcock was indeed correct to note that it will be at least a year before inhaled insulin is used in clinical practice. This error was noted soon after the article went to press and a correction to this effect appeared on the Thorax website before the article appeared in print and on page 978 of the November 2000 issue of Thorax. ${ }^{1} \mathrm{He}$ is, however, incorrect in both his estimation of the complexity of the device and of its likely price; any increase in cost will not be attributable to the production of the device but the premium charged for a novel form of treatment. The issue was raised to illustrate the point that simple to use, effective devices can be developed to serve specific functions.

My views on compliance are far from paternalistic. As noted in the article, noncompliance is common in all diseases and the factors contributing to it are complex. There are no easy solutions for an issue that is responsible for excess morbidity, mortality, and healthcare costs. However, modern technology can certainly impinge on this area since, as Professor Morice notes, it is possible not only to monitor whether a device is used but also to monitor whether the device is used correctly. Monitoring compliance is likely to be introduced in North America if managed care organisations find that they can reduce costs. I do not know if patients or doctors want such facilities in their delivery systems, but since it is now possible to monitor compliance in this way, a grown up, informed debate should be initiated. Certainly, objective compliance data can significantly improve the quality of a consultation by allowing the patient and professional to concentrate on the factors adversely affecting compliance in an open and honest dialogue.

It is to be hoped that in the future novel devices will use appropriate technology to meet the needs of the patient rather than developing devices that force patients to adapt to the technology.

$$
\begin{array}{r}
\text { Paediatric Respiratory Unit, } \\
\text { Sheffield Children's Hospital, } \\
\text { Sheffield S102TH, UK } \\
\text { m.l.everard@sheffield.ac.uk }
\end{array}
$$

M L EVERARD

1 Correction. CFC transition. Thorax 2000;55:978.

\section{Time to consign cromoglycate to history?}

Sodium cromoglycate (SCG) has become a minority option for the treatment of childhood asthma, ${ }^{1}$ and even positive trials show only marginally relevant differences in the outcomes measured. ${ }^{2}$ It is therefore interesting to recall that in 1967 the majority of asthmatic subjects were exposed to cigarette smoke and many had deformed chests. Children were not allowed to self-medicate or to receive their treatment at ordinary schools; the most affected were sent to special schools and camps. Oral ephedrine and short acting theophylline preparations were standard 
treatment, but their effectiveness was limited by tachyphylaxis.

The children who were treated with SCG when it was introduced experienced less the currently available alternative - dry powder inhalers - are perceived to be more costly. exercise induced asthma and were able to participate in playground games, often for the first time. In addition, fewer colds resulted in wheezing and exacerbations were shorter. The parents and physicians of these children were delighted with this safe remedy which was effective for all but the most severe forms of the condition. The most popular formulation was a mixture of SCG with isoprenaline (Intal compound). This combined the immediate bronchodilator effect of a rapidly acting $\beta$ adrenergic drug of extremely short duration with protection from antigen challenges and exercise induced asthma which lasted for about 6 hours.

Salbutamol was introduced in 1969 , only 2 years after SCG, and had the same effect in providing both relief and protection. As soon as salbutamol, permitted 6-hourly, became the rescue bronchodilator of choice, it became difficult to demonstrate any clinically relevant benefit attributable solely to SCG in patients who were not dependent on oral steroids. Inhaled beclomethasone was introduced soon afterwards and this enabled even more asthmatics who were dependent on oral steroids to discontinue them. Beclomethasone does not have the unpleasant taste that makes SCG disagreeable to use, and suppresses more components of inflammation than SCG. Furthermore, beclomethasone rapidly reduces symptoms more effectively for the same effect on daytime $\mathrm{FEV}_{1}$ and morning peak flow, possibly by reducing the sensation of inflammation in the airways. ${ }^{3}$ By the time it was recognised that long term administration of higher doses of inhaled steroids produced significant side effects in children and adults, long acting bronchodilators had been developed and proved to be useful in combination with medium doses of inhaled steroids. The possible use of cromoglycate, with its proven safety record, was not investigated in this context. There are no long term studies which show whether SCG played any part in the improved outcomes in childhood asthma between 1970 and 1980, or whether these are entirely the consequence of inhaled steroid use.

In a lucid contemporary account, one of the first investigators to test SCG described how he and his colleagues were disappointed to be unable to show any major effect of SCG on $\mathrm{FEV}_{1}$ in spite of a dramatic symptomatic and steroid sparing effect. ${ }^{4}$ At this time asthma was defined as variable or reversible airflow obstruction, and it was recognised that patients would judge the control of their condition by the frequency of regular, unexpected, or nocturnal attacks rather than by their best lung function. The value of frequent observation during the day was demonstrated by Chai et $a{ }^{\Gamma}$ in 1968 and accepted in the late 1970 s even by physicians who had previously regarded paroxysmal nocturnal dyspnoea as synonymous with pulmonary oedema.

Helms $^{1}$ points out that regulators and authors of meta-analyses have a duty to examine appropriate outcomes. To promote informed discussion, they also need to be aware of the changing therapeutic options that were available when the studies under scrutiny were carried out.

G LASZLO

Consultant Physician Emeritus, Bristol Royal Infirmary, Bristol BS2 8HW, UK GLaszlo11@aol.com

1 Helms PJ. Inhaled disodium cromoglycate as maintenance therapy for childhood asthma:

2 Tasche MJA, Uijen JHJM, Bernsen RMD, et al. Inhaled disodium cromoglycate (DSCG) as maintenance therapy in children with asthma: a systematic review. Thorax 2000;55:913-20.

3 Higgs CMB, Laszlo G. Influence of treatment Higgs CMB, Laszlo G. Influence of treatment
with beclomethasone, cromoglycate and theophylline on perception of bronchoconstriction in patients with asthma. Clin Sci 1996;90:227-34. 4 Greenberg MJ. Disodium cromglycate. In: Marsh BT, ed. A symposium on reversible airways obstruction, 8 May 1969. Sponsored and circulated by Allen \& Hanbury's, London, 95-101.

5 Chai H, Purcell K, Brady K, et al. Therapeutic and investigational evaluation of asthmatic children. $\mathcal{F}$ Allergy 1968;41:23-36.

AUTHORS' REPLY Lazlo provides an historical perspective on the passing cromoglycate era in which he describes the dire state of asthma management, particularly in children, at the time that sodium cromoglycate (SCG) was introduced. He also points out that, soon after SCG was introduced, inhaled isoprenaline became available followed by the selective $\beta_{2}$ agonist salbutamol. Although isoprenaline in combination with SCG was common in adult practice, it was used much less frequently in children. There are a number of other child/adult differences in practice and effectiveness that underline the insecurities of extrapolation and inference. ${ }^{1}$ The protective effects of cromones on exercise induced bronchoconstriction are established, but are of relatively short duration $^{2}$ and are therefore unlikely to provide reliable and sustained protection against this troublesome symptom in active children. Whereas long acting $\beta$ agonists have proved to be useful in combination with moderate doses of inhaled steroids in adults, ${ }^{3}$ the effects in young children have been disappointing $^{4}$ and have been the subject of a narrative review. ${ }^{5}$ Extrapolation of experience from predominantly adult studies into the paediatric age range has been a feature of asthma management but is increasingly being shown to be insecure, again emphasising the need for studies in children, particularly in those in younger age groups where the disease is most prevalent. ${ }^{1}$ There is at least one long term study which attempted to assess the effectiveness of SCG and which concluded that $60-70 \%$ of children with persistent symptoms improved over a 3-5 year period. ${ }^{6}$ However, this study, which was an open extension to a formal double blind placebo controlled trial, could not take into account the natural rates of resolution and recurrence of the disease over this prolonged period.

Despite the popularity of SCG in the 1970s and early 1980s, it could be argued that its marginal effectiveness, masked by its combined use with effective bronchodilator agents, together with concerns about possible systemic effects of steroids prolonged its appearance in the therapeutic armamentarium. The passing cromoglycate era certainly contains many lessons for the prescribing community, and among these must be an awareness of the natural history of the disease in childhood and the potential pitfalls of extrapolating lessons learnt in more severely affected and older age groups into younger age groups.

P J HELMS Department of Child Health, University of Aberdeen, Foresterhill, Aberdeen AB25 2ZD, UK p.j.helms@abdn.ac.uk

1 Helms PJ. Inhaled disodium cromoglycate as maintenance therapy for childhood asthma: time to consign to history? Thorax 2000;55:886.

2 Spooner C, Rowe BH, Saunders LD. Nedocromil sodium in the treatment of exerciseinduced asthma: a meta-analysis. Eur Respir $\mathcal{F}$ 2000;16:30-7.

3 Greening AP, Ind WP, Northfield $\mathrm{M}$, et al. Added salmeterol versus higher-dose corticosteroid in asthm patients with symptoms on steroid in asthma patients with symptoms on 344:219-24.

4 Verberne AAPH, Frost C, Duiverman EJ, et al. Addition of salmeterol versus doubling the dose of beclomethasone in children with asthma. Am 7 Respir Crit Care Med 1998;158: asthma.

5 Bisgaard H. Long-acting $\beta_{2}$-agonists in management of childhood asthma: a critical review of the literature. Pediatr Pulmonol 2000;29:22134.

6 Godfrey S, Balfour-Lynn L, Konig P. The place of cromolyn sodium in the long term management of childhood asthma based on a 3 to 5 year follow up. $\mathcal{F}$ Pediatr 1975;87:465-73.

7 Strachan D, Gerritsen J. Long-term outcome of early childhood wheezing: population data. Eur Respir f Suppl 1996;9:42-7S.

AUTHORS' REPLY We appreciate Dr Laszlo's eloquent historic overview of asthma treatment and agree that a therapy should be considered within the range of available options. This range of options may change over time. However, our systematic review addressed the effectiveness of sodium cromoglycate compared with placebo, not with other active treatments. As a consequence, our findings may be a guidance not only to today's physicians but also to future generations with other therapeutic alternatives.

M J A TASCHE
J H J M UIJEN
R M D BERNSEN
J C DE JONGSTE
J C VAN DER WOUDEN
Department of General Practice and Division of
Pediatric/Respiratory Medicine,
Erasmus University and University Hospital/Sophia
Children's Hospital,
Rotterdam,
The Netherlands
vanderwouden@hag.fgg.eur.nl

\section{BOOK REVIEW}

Law for Doctors: Principles and Practicalities. Margaret Branthwaite. (Pp 84, paperback; £7.50). London: Royal Society of Medicine Press, 2000. ISBN 1 853154652

Margaret Branthwaite, formerly a distinguished consultant physician at the Royal Brompton hospital, retired early from her post to train in law and is now a barrister. She is therefore uniquely well qualified to write a book explaining the law as it impinges upon medical practice for doctors. She also writes with admirable conciseness and clarity and the book is a pleasure to read. 
Not many years ago most doctors regarded interaction with the law with a combination of distaste and fear, and I remember being advised by a very senior colleague to eschew contact with lawyers as far as possibleadvice which I am glad I did not take. Nowadays doctors are increasingly aware of the need to have at least a passing acquaintance with the law, both in order to help their patients and to protect themselves against potential litigation for malpractice. The former consideration applies particularly in respiratory medicine where disease of occupational origin is common and patients look to their respiratory physician for advice about seeking compensation.

This book covers all the important interfaces between medicine and the law. There is a clear exposition of the legal basis for claims for damages arising from clinical practice. The criteria for a finding of negligence and the basis for the calculation of damages are explained. The legal steps involved in pursuing a claim for damages for personal injury (a term which includes occupational lung disease) are set out. The important changes to the requirements of expert witnesses introduced as the Woolf reforms last year are described.

Other areas in which the law impacts upon medicine are considered including the concept of informed consent for both adults and children. Complaints, whistle blowing, and disciplinary proceedings are discussed briefly. There is a useful explanation of the work of the Coroner's court and the doctor's role in its proceedings. Finally, there is a stimulating discussion of issues surrounding allegations of homicide and manslaughter against doctors and the potential criminal liability for end of life decisions.

I would strongly recommend this modestly priced book to all readers who are at all interested in the interface between the law and medicine, and to those who may be less interested but feel they should be better informed.- $\mathrm{RR}$

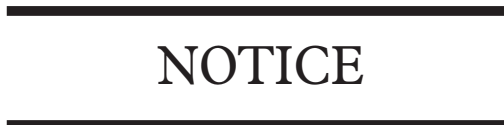

\section{Respiratory Medicine}

A conference on Respiratory Medicine will be held at the Royal College of Physicians of Edinburgh on 26 October 2001. For further information contact Ms Eileen Strawn, Symposium Coordinator. Telephone 0131225 7324. Fax 0131220 4393. Email: e.strawn@rcpe.ac.uk. Website: www. rcpe.ac.uk.

\section{TB at the end of the 20th century}

In the paper entitled "Tuberculosis at the end of the 20th century in England and Wales: results of a national survey in 1998" by A M C Rose et al which appeared on pp 173-9 of the March 2001 issue of Thorax, the data for the South East region were omitted from table 3 on page 176 of the paper. The correct version of the table is shown here. The authors apologise for this omission.

Table 3 Number of patients with tuberculosis and rate of disease by NHS region and in district health authorities in England and Wales with more than 100 tuberculosis patients and/or a rate of $>25$ per 100000 in 1998

\begin{tabular}{lccc}
\hline & \multirow{2}{*}{ No of cases } & Rate & $95 \%$ CI \\
\hline Region & & & \\
$\quad$ London & 2244 & 31.6 & 31.2 to 32.1 \\
West Midlands & 625 & 11.9 & 11.7 to 12.0 \\
North West & 662 & 10.2 & 10.1 to 10.4 \\
Northern \& Yorkshire & 605 & 9.67 & 9.52 to 9.81 \\
Trent & 443 & 8.68 & 8.53 to 8.82 \\
South East & 460 & 5.75 & 5.67 to 5.83 \\
Wales & 163 & 5.70 & 5.58 to 5.83 \\
South West & 212 & 4.41 & 4.34 to 4.49 \\
Eastern & 244 & 4.22 & 4.16 to 4.29 \\
District health authority & & & \\
East London \& The City & 377 & 61.5 & 58.7 to 64.6 \\
Ealing, Hammersmith \& Hounslow & 346 & 52.2 & 49.9 to 54.7 \\
Brent \& Harrow & 217 & 47.1 & 44.7 to 49.9 \\
Enfield \& Haringey & 194 & 40.2 & 38.1 to 42.5 \\
Camden \& Islington & 143 & 40.1 & 37.7 to 42.8 \\
Redbridge \& Waltham Forest & 144 & 32.1 & 30.4 to 34.0 \\
Lambeth, Southwark \& Lewisham & 231 & 31.3 & 30.0 to 32.8 \\
Kensington, Chelsea \& Westminster & 114 & 30.9 & 29.1 to 33.0 \\
Bradford & 139 & 29.1 & 27.6 to 30.7 \\
Hillingdon & 70 & 28.2 & 26.2 to 30.5 \\
East Lancashire & 114 & 28.0 & 26.6 to 29.6 \\
Calderdale \& Kirklees & 151 & 26.1 & 24.9 to 27.5 \\
Croydon & 87 & 26.0 & 24.4 to 27.8 \\
Birmingham & 247 & 24.6 & 23.7 to 25.5 \\
Leicestershire & 172 & 18.7 & 18.0 to 19.5 \\
\hline Apil & & &
\end{tabular}

^April 1999 boundaries.

$\star \star$ Rate per 100000 population.

Source of population data: Labour Force Survey Local Area District database to 1998. 